\title{
THE CONSTRUCTION AND ACTIVATION OF LANGUAGE USERS' BACKGROUND SCHEMATA IN MEDICAL DOMAIN DISCOURSE
}

\author{
Mikhail Demidov ${ }^{1}$, Ksenia Anisimova $^{2}$, Svetlana Rubtsova $^{3 *}$ \\ ${ }^{1,3}$ Saint Petersburg State University, Faculty of Modern Languages, Russia \\ ${ }^{2}$ Saint Petersburg State University, Centre for Additional Educational Programs, Russia \\ "E-Mail: rubtsova_svetlana@mail.ru
}

\begin{abstract}
Schema theory postulates that background knowledge facilitates and speeds up communication. According to the Common European Framework of Reference for Languages (CEFR), human communication is dependent on this knowledge, and language users are expected to have the appropriate level of world knowledge across a number of domains. PACTE group at Autonomous University of Barcelona is currently designing a similar framework for translators, and emphasises to the same degree the importance of background knowledge. While the practical need for background knowledge across specialised domains in language learning and in translation has been shown, the specific ways of capturing, organising and making it available for future users remains to be elucidated. The authors of this paper observed two professional interpreters prepare, produce an interpretation, and reflect on their work in the context of a conference in veterinary surgery. On at least four occasions the interpreters felt that their saturation levels were exceeded, and they self-reported the probable disruption in communication. During the follow-up interview they attributed the four problematic situations to their limited understanding of certain concepts that the speaker had chosen to refer to. We identified the exact pieces of information that the interpreters felt they lacked, and worked out a form of capturing, organising and transferring such information so that it be will a natural extension of the traditional self-preparation process. We propose two concepts: (1) The Index of Sophistication to predict the degree of professional complexity of a given text; and (2) A multilingual explanatory Databank, organised as a series of overlapping semantic networks that could help language users visualise and internalise schemata in medical domain. We believe that this work has implications for interpreter/translator training, as well as for teaching English for Medical Purposes. By implementing the Index of Sophistication and the Databank, at least for some medical specialties, we could facilitate greater precision and validity of medical translation.
\end{abstract}

Key words: background schemata, medical English, trauma and orthopedics, Databank, anticipation strategy, Index of Sophistication, Tight Rope Hypothesis 


\section{INTRODUCTION}

The association between one's background knowledge and their language comprehension is reflected in schema theory, whereby any text is seen as a rough guide to reconstructing the intended meaning based on individual's prior knowledge, rather than the source of meaning per se (Carrell 1984b:332). A classical definition of schema by Bartlett describes it as individual's past experiences and past reactions that are organised in series and are manifested in a particular response to an incoming impulse of a particular kind (Bartlett 1932:201). Rumelhart defined schema as: ".... data structure for representing the generic concepts stored in memory" (Rumelhart 1980:34).

Either of the definitions entails individual's prior interactions with the world. Reading comprehension warrants the knowledge of text structures, as well as knowledge of the world (Barnitz 1986:95; Carrell 1984a:87). Common European Framework of Reference for Languages (CEFR) asserts that "All human communication depends on a shared knowledge of the world" (Council of Europe 2001:11), and mentions "Knowledge of the World" among other general competences that language learners or users are expected to have (e.g. Council of Europe 2001:30). PACTE research group from Autonomous University of Barcelona, which is working on Establishing Competence Levels in the Acquisition of Translation Competence in written Translation (NACT project), seeks to produce a similar type of framework for translator training and professional translation (Hurtado Albir 2018:112). PACTE's proposed "Descriptive Categories for Translation Competence" include world knowledge and thematic competence among other categories (Hurtado Albir 2018:120).

World knowledge and thematic competence are implied by the action-oriented approach adopted in CEFR, as it: “... views users and learners of a language primarily as 'social agents', i.e. members of society who have tasks (not exclusively language-related) to accomplish in a given set of circumstances, in a specific environment and within a particular field of action." (Council of Europe 2001:9).

Alongside the world knowledge, CEFR sets out another important component of communicative language competence, namely, mediation activities, including translation or interpretation (Council of Europe 2001:14). In view of the above, it would not be unreasonable to see a degree of equivalence between an interpreter, a translator, a language learner, and a language user in that each of them are 'social agents' who rely on their schemata to accomplish their very different communicative tasks.

Further overlap between a language learner/user and a translator/interpreter can be observed in the context of Language for Specific Purposes (LSP) approach. Although the exact meaning of translation in LSP is somewhat different from professional translation (Cohen 2001:101), the translation process remains a strategic tool for successful communication (ibid 102). On the other hand, CEFR makes a case for communication strategies, and puts at their core the principles of Pre-planning, Execution, Monitoring and Repair Action (Council of Europe 2001:57). Monitoring of communicative processes, in turn, is viewed as a strategic task, particularly when the domain or the theme schema change, or when mishearing occurs (ibid 93). The multi-component nature of communication is apparent in LSP, where two-fold competence is instrumental: general language competence and professional language competence (e.g. Rackevičienė et al. 2019:138; ALTE 2018:5).

In this paper we equate interpreters/translators with language users mainly because of PACTE's proposed competence levels. In a recent publication the Group recommends the 
language competence level of translators to be as high as CEFR B2 - C2 (Hurtado Albir 2018:120). Meanwhile, CEFR emphasises that C2 level typifies the speech of highly successful learners, but in no way is it intended to mean native-speaker competence (Council of Europe 2001:36). Furthermore, PACTE's proposed "Global scale and examples of cultural and world knowledge for interpreters/translators" (see Hurtado Albir 2018:125 - 130) seem to fit the occupational and public domains envisaged by CEFR for language learners (Council of Europe 2001:45). In this paper schemata are understood as mental representations of typical instances that speed up communication (see Salbego 2016:177).

The approach used by the authors of this paper has its foundations in the fundamentals of semiotic theory by C.S. Peirce (Peirce 1977). In particular, the authors stick to the idea of triadic signs and contrast between a Sign (or a representamen, or sign vehicle), a Semiotic object, and an Interpretant. The authors also share the basic principles of the second signaling system theory by I.P. Pavlov (Pavlov 1927).

The authors also use the terms 'concept', 'scope of a concept' and 'meaning of a concept' as follows. The term 'concept' is used as equivalent of phenomenon, i.e. a real-life entity that may be observed or found by means of special examinations/investigations. The authors use the term 'sign' to refer to the reflection of a concept in a given language. For example, the concept of chronic and irreversible damage to the airway that causes its obstruction is denoted by the sign of 'COPD' in English, and the Sign of 'ХОБЛ' in Russian. This is consistent with one of the postulates of Pavlov's theory that words are a replacement of real-life phenomena in the human mind: “...speech provides conditioned stimuli which are just as real as any other stimuli. Speech ... is connected with all the internal and external stimuli... signaling all of them and replacing all of them, and therefore it can call forth all those reactions of the organism which are normally determined by the actual stimuli themselves" (Pavlov 1927:407).

By the 'meaning of a concept' the authors mean a set of differential features pertinent to the correspondent phenomenon (i.e. in case of COPD this will mean a set of clinical and morphological criteria that are required to establish the diagnosis of COPD). By the 'scope of a concept' the authors mean the set of phenomena that may be covered by a given meaning of a concept (i.e. COPD stages). For the purpose of this paper, 'semiotic object' amounts to the 'meaning of the concept' plus the 'scope of the concept', as reflected in a given language. In other words in our example it covers the definitions of COPD and its stages provided by clinical guidelines, as well as layman definitions in any given language. Furtheron, the 'interpretant' amounts to the 'meaning of the concept' plus the 'scope of the concept', as reflected in an individual's second signaling system. The fact that the interpretants of different individuals overlap to a certain degree makes communication and, indeed, interpreting/ translating possible. 'Interpretant' and 'schema' are used interchangeably.

We would like to provide an example of professional interpretation of two speeches at a conference on surgery, where the domains and schemata were changing. Even though a number of well-known translation strategies were implemented and attempts to pre-plan, monitor and repair the communication were made, still occasional disruptions of communication and less successful monitoring occurred. We presume that with a special tool in place, such as a multilingual databank of medical English, the language users' background schemata might be better activated, with the consequent improvement in the efficacy of communication. 


\section{THE EXTENT OF BACKGROUnd SCHEMATA In MEDiCAL Domain Discourse THAT USERS ARE EXPECTED TO HAVE}

The work of an interpreter can probably be compared to journalism: you have to tell a story about something that you may have never known before, moreover it should be credible, at least with no major inaccuracies, and its wording should sound familiar to the connoisseur's ear. You may not necessarily know the tricks of the trade, but you should pretend as if you do. As the New York Times reading room blog has put it: "The quality of a translation goes not just to accuracy of detail or intent, not just to felicity of language, but to clarity, nuance and credibility" (Keller 2007).

One of the guidelines for medical interpreters could provide another relevant example: "California developed interpreting services, sometimes as the result of a lawsuit, a critical patient-care incident, or a desire to improve their services" (CHIA 2002:18). Among other provisions, the guideline lays out a number of principles pertaining to accuracy and completeness of interpretation. In particular, the document says that the interpreter should: "Notify the parties of any medical terms, vocabulary words, or other expressions which may not have an equivalent either in the English or target languages, thus allowing speakers to give a simplified explanation of the terms, or to assist speakers in doing so" (CHIA 2002:31). In other words, the knowledge of medical terms and their correspondences across a language pair is viewed as the interpreter's domain.

On the other hand, the document recognises that interpreters: “...could be working with individuals with difficult personalities, calming an agitated or fearful patient, or interpreting complex subject matter and technical terminology" (CHIA 2002:38). The document, therefore, accepts that the interpreter may not necessarily know the ins and outs of the subject matter. Furthermore, the document refers to the Incremental intervention model by Avery and Roat which is being used by Cross Cultural Health Care Program at Seattle: "This model recognises that the very presence of an interpreter in the patient-provider encounter is an 'intervention' with the potential of positively or negatively impacting patient-provider relationships and outcomes" (CHIA 2002:49).

To sum up all of the above, the guideline raises the need for accurate, comprehensive and minimally invasive interpreting, while recognizing that it may be a complex and technical task for an interpreter. At the same time, the document is not specific about the type of educational background that a healthcare interpreter should have. PACTE offers a more detailed description by postulating that B2 and B1 translators should have world knowledge comparable to secondary education level, while C-level translators' amount of world and thematic knowledge should correspond to the one required in professional practice (Hurtado Albir 2018:130). Meanwhile, some of the terms in which CEFR proposes to describe the situations of language usage include: institutions, events, and operations (Council of Europe 2001:46), which translates into a large body of data in medical domain.

\section{Possible Procedures that Language Users CAN Adopt TO INTERNALISE THE SCHEMATA}

In view of the above, a reasonable way to internalise background schemata in medical domain discourse would be to: gather relevant and comprehensive background, and figure out the main concepts that a given specialty deals with, as well as the corresponding terms (i.e. signs) and the relations (i.e. predicates in terms of first-order logic) between the 
concepts. This body of information should be arranged in an easy-to-use template and regularly reviewed. A parallel can be found in guidelines for journalists, some of which, for example, agree in that accuracy checklists need to be used. The information about a news story has to be permanently updated, and every fact needs to be checked by addressing at least two sources (https://ethics.journalists.org/topics/accuracy/ or https://www.spj.org/ ethicscode.asp). For interpreters/translators, this would mean a special self-preparation procedure. The interpreter, for example, could try to anticipate the possible line of speaker's thought by reading up some of their articles, watching some of their interviews, or, at least, by making an inference based on the speaker's list of publications. This approach has its foundations in the anticipation theory by Ghelly Chernov (1978). As he puts it, anticipation can come in different forms: "...either the interpreter actually says a word (the verb for instance) before the speaker has uttered the corresponding word, or, more commonly, he puts in a word at the correct place... in his own language that there is no doubt the interpreter summoned it before hearing the original" (Chernov1978: 138-139). One more form could be to make: “...assumptions about how the speaker's intention is likely to develop or be completed semantically and verbally" (Chernov 2004: 185).

Some of the questions that need to be addressed by language learners, who seek to comprehensively use their language, according to CEFR, include the following: whether or not one can predict the domains in which they are going to operate; what knowledge of the world they will need to have; what the best way to prepare for the usage of language in given circumstances is; and what objects they will have to refer to (Council of Europe 2001:44). The following section provides an example of how language users tried to address these issues in the context of interpreting two speeches at a conference on veterinary surgery. The section seeks to demonstrate that traditional self-preparation, including terminology research, inference and anticipation, has most likely been insufficient. In order to avoid any unintentional advertising or possible conflict of interests we cannot go into further details as to the conference name, time, place, or organiser.

\subsection{Observation of language usage}

\subsubsection{Learner profile and context}

Two professional interpreters (referred to as 'interpreters') were expected to provide interpreting for two speeches on pelvic trauma delivered by a native English speaker who had extensive practical and academic background. Both of the interpreters had master's degrees in interpreting, as well as post-grade training and working experience, including at medical events. However, they had no systemic medical training, which in itself rarely occurs among interpreters.

Because one of the authors (Mikhail Demidov) holds the university degrees both in interpreting and in human medicine, he acted as a chief interpreter at the conference. A part of his responsibilities was to appoint other interpreters to translate particular speeches and to consult them in the course of their preparation for the meeting. The team (i.e. the chief interpreter and the interpreters) had been forwarded the lecture slides in advance. Well before the event the team met several times for a series of briefings and worked through the presentations. The chief interpreter kept a paper record of the questions that the interpreters asked before the event and grouped their questions by categories. The chief interpreter was present at the venue during the meeting and backed up the interpreters when asked to do so (took a turn in the booth to interpret simultaneously). The team then had a feedback briefing 
to elucidate the nature of difficulties that the Interpreters had faced. The chief interpreter also kept paper record of these conversations. As the Tight Rope Hypothesis by Daniel Gile suggests, a high proportion of omissions and errors should be expected only if interpreters work close to their saturation level (Gile, 1997, 1999). The feedback briefing was expected to reveal the saturation levels during the difficult episodes.

\subsubsection{Procedure}

The lecture plan went as follows List $1^{1}$, so it immediately gave the impression of being a challenging one, mainly because of the number of subjects to be covered.

List 1:

- Assessment and Triage

- Urinary tract issues

- Neurological issues

- Pelvic fractures

- Post-op management

- Tube cystostomy placement

In linguistic terms, this meant recalling a number of lexico-semantic fields that may seem totally unrelated. Furthermore, any attempt to anticipate the speech is very likely to have limited efficacy. This is because the free flow of the speech would make it very variable word-wise and subject-wise. For example, the following slide (List 2) gave the chief interpreter the impression of being a plain one. It seemingly provided bare facts, of which, probably only the acronyms 'HL', ' $\mu$ agonist' and 'BUN' needed some clarification for the Interpreters. The interpreters' attention, however, was also drawn by the acronyms 'iv', 'im', and 'sc'. Some brief explanation of drug classes, in particular, opioid analgesics vs NSAIDs, as well as their applications was needed, too. All the rest seemed to be a mere enumeration of facts for the sake of an overview.

List 2:

- Analgesia after assess HL and Pudendal function

- Full u agonist opioid 000mg/kg im, slow iv, sc, q4h

- Partial u agonist opioid 000mg/kg im, slow iv, sc, q6h

- NOT X

- NSAIDS (not usually in first 24 hours)

- Must be fully hydrated

- good renal function (BUN/Creatinine)

Interestingly, the speaker spent some time providing a pathophysiologic explanation behind the NSAIDs ability to injure kidneys in a shock patient (i.e. those having, inter

\footnotetext{
${ }^{1}$ In order to avoid possible conflict of interests and/or unintended advertising, the original slides are not provided. Instead, plain text is given. The original text has been modified in the following ways: proper names have been replaced by ' $\mathrm{X}$ ', ' $\mathrm{Y}$ ', or ' $Z$ '; original numbers have been replaced by ' 000 ', unless important for illustration; some technical details, wordings and descriptions have been removed. We attempted to select and modify the slides in such a way that the modified version could still convey the points relevant for the aims of this paper.
} 
alia, critically low blood pressure and poor tissue perfusion). He emphasised that prostaglandin (PG) synthesis was vital in maintaining normal renal function, whereas NSAID class of drugs was designed to inhibit the PG metabolic pathways, known to play a crucial role in inflammation and pain sensation. This effect, therefore, posed a degree of risk for poorly perfused kidneys. In this fashion the speaker revealed the need to provide adequate hydration first, as well as to consider the kidney function by measuring the levels of BUN and creatinine.

List 3: Concurrent trauma and differential diagnosis

\begin{tabular}{|c|c|}
\hline \multicolumn{2}{|c|}{$\begin{array}{l}\text { Concurrent Urinary Trauma } \\
\text { - Urethral/bladder damage common } \\
\text { - } \text { Dx positive contrast retrograde urethrocystogram } \\
\text { - Small tears treated by X } \\
\text { - Ureteric/renal leakage uncommon } \\
\text { - } \quad \text { Dx IV excretory urogram }\end{array}$} \\
\hline \multicolumn{2}{|c|}{ Diagnostics } \\
\hline $\begin{array}{l}\text { Retro-urethrocystogram } \\
\text { Non diluted X } \\
{[\text { X-ray] }}\end{array}$ & $\begin{array}{l}\text { IVU - rarer } \\
{[\mathrm{X} \text {-ray }]}\end{array}$ \\
\hline
\end{tabular}

The speaker then changed gears. His slide on concurrent urinary trauma (List 3) provided a distinction between the occurrence of the two disease entities (urethral vs ureteric damage), as well as the indications for their treatment. Meanwhile, the Diagnostics slide outlined the two respective diagnostic techniques (retro-urethrocystogram vs IVU - intravenous urography).

The Concurrent urinary trauma slide was \#15, whereas the Diagnostics slide was $\# 23$. The slides in between changed very fast, each taking the speaker more than a minute to talk about. This translated into at least 8 minutes of discussing genitourinary trauma: a new subject (i.e. a digression) incorporated into the presentation that had initially seemed to have purely an orthopaedic nature. Furthermore, the distinction between 'the ureter' and 'the urethra', as well as the relevant diagnostic techniques, is so obvious for a professional, that slide \#15 was the only one that expressly outlined this distinction. The rest of the eight-minute talk was dedicated to an overview of technical details that may help in revealing one of those injuries or the other. Next came the slide that clearly demonstrated the need for knowing the extralinguistic context. It was dedicated to neurological manifestations of orthopaedic injuries.

List 4: A slide that will make no sense for an interpreter unless they pick up some extralinguistic background

Concurrent Neurological
- Assess HL deep pain and pudendal reflexes
- Assess HL deep pain ( \pm withdrawal = spinal reflex $)$
- Pinch toes - look for 'cranial response'
- Assess bladder tone careful palpate \pm manual expression if tolerated
- Assess tail mobile/flaccid


Even though this is not about in-depth neurology, it still can pose significant difficulties for an interpreter. The slide above has a number of acronyms (that distract certain amount of attention and approximate the workload to the saturation level), while also mentioning some seemingly unrelated concepts. 'HL' stands for hind limb, 'UMN' and 'LMN' stand for upper and lower motoneuron, respectively. However, in this particular case the following concerns were voiced by the Interpreters:

- 'Pudendal nerve' has been mentioned, so what do upper and lower motoneurons have to do with it? Where are they localized?

- The slide mentions 'cranial response', while the pudendal region seems to be in a different location; what does the skull have to do with the anus?

- Why are 'haemostats' mentioned, even though there is nothing said about haemorrhage?

- What are 'withdrawal' and 'expression' supposed to mean in this context?

As the presentation continued, there followed some more challenges. However, we find it practical to limit our case example to the abovementioned facts.

\subsection{Suggested procedures for the construction and activation of schemata in medical domain discourse}

The observations that we have made bring us to the conclusion that language users would benefit greatly from an explanatory Databank that would reflect semiotic objects and relevant predicates, as well as certain extralinguistic background in various fields of medicine in a number of languages. Not only can it provide validated equivalents (that are impossible for a single interpreter/translator to collect and verify during their routine preparation), but also can address the ever changing hot spots, in order for the interpreters/translators to quickly get updated on the latest developments in a particular topic. This would be in line with the modern-day trend of reading up for a meeting from the event-specific content (Horváth 2016:184). A certain briefing of interpreters/translators is normally expected from a client, but it does not necessarily cover the whole range of concerns that interpreters/translators may have. Furthermore, unlike a conventional dictionary, a Databank can incorporate important metadata: including a particular domain to which a concept in question applies, the date, the time and the source of a particular entry. This may help choose the most recent and reputable material, while ignoring the outdated (Moorkens 2013). An example of metadata being used in a similar fashion can be found at InterActive Terminology for Europe (IATE) website at http://iate.europa.eu/SearchByQueryLoad.do?method=load.

The proposed Databank could be web-based. It could be run by an interdisciplinary multilingual team of linguists, medical doctors, interpreters/translators and other professionals, e.g. IT-professionals. The proposed Databank could have a form of a mind-map/semantic network, or, rather, overlapping mind-maps/semantic networks, one for each language, due to the intrinsic asymmetry of signs in different languages. Such a mind-map/network could provide the interpreters/translators with important concepts, their relations, both linguistic and extralinguistic, as well as the appropriate wordings in a given pair of languages. On the other hand, the alternatives to the mind-map/semantic network, as well as the best way to present the information should probably become a subject of a targeted survey among prospective users.

We do not pretend to duplicate in any way the great job already done. The Mayo clinic education portal, Medscape reference, Radiopaedia, Merck manual are only some 
of the examples of top-notch web resources that interested language users can exploit in order to have the edge. The usage of such resources for linguistic purposes, however, is complicated by several factors: (a) most of them are aimed for healthcare professionals, i.e. require certain background knowledge; and (b) all of them are monolingual.

The authors are of the opinion that monolingual sources can be very useful, yet not enough. They can help language users at an advanced level, whereas the proposed Databank could bridge a gap to interdisciplinary communication at earlier stages.

The practical steps to build such a Databank may include the following:

- To conduct a survey similar to the one that we described in our case example. It may help determine the most complicated areas in medicine for a representative group of linguists. The survey can also elucidate the interpretants behind a number of important concepts. Those interpretants can later be compared to the interpretants obtained from a representative group of medical doctors;

- based on this information, the Index of Sophistication can be worked out. This index would be meant to become a measure of how difficult a particular medical topic is likely to be for a translator/interpreter. The index could take into account the particular patterns of extralinguistic reference pertinent to a particular topic and, therefore, be predictive of the expected workload during the interpreter's preparation;

- Another survey can help design the uniform template of the Databank. In other words, a form of representing the information, for example: (a) the information is easy to perceive, (b) the translation equivalents are easy to pick up, (c) the template is easy to update, (d) most of the interpreters/translators in the survey find the presentation handy and natural (i.e. it fits the personality type/personality types that is/are dominant among interpreters/translators);

- to build a number of monolingual semantic networks across a number of medical specialties;

- to build links between the correspondent monolingual semantic networks. As a result, a three-dimensional network of validated equivalents is expected to appear.

\section{DISCUSSION AND CONCLUSION}

In the authors' opinion, those ESP language users who perform exclusively languagerelated tasks, i.e. translators/interpreters, would feel more comfortable and confident about their professional communication if it is consistent (i.e. no mistranslation is present), coherent (i.e. the logical links are obvious to the interpreter), and relevant (i.e. interpreting is delivered plausibly with the appropriate wordings). As the chief interpreter at the conference, one of the authors found it important to closely communicate with the interpreters over the course of the event. The chief interpreter was appointed to his position by his client due to his vast experience in medical interpreting, as well as due to the double degree: in interpreting and in human medicine. Therefore, his obligation was to help his colleagues provide the best available level of services. In the follow-up to the meeting the chief interpreter interviewed the interpreters about the difficulties they had had. A paper record of the interview was kept. The interpreters were asked about the following: the number of occasions on which they felt uncomfortable or unsatisfied with their work; what exactly caused difficulties; if the difficulty was about words or schemata; and whether they felt at or above their saturation level on these occasions. The 
interpreters thought that their saturation levels had been exceeded several times. They said that individual words did not pose difficulties to them, especially with online dictionaries being available during the conference. Rather, the difficulties were very much about schemata. The interpreters pointed out specifically the following situations.

Elements of schemata that the communicative task required:

(1) The first observation refers to List 2 . Though the slide explicitly mentioned a list of facts, they could not fit into a coherent story in layman's perception. Rather, they looked like another enumeration of unrelated items. If not elucidated properly, the logical link (i.e. extralinguistic context) between the NSAID class of drugs and the reasons behind not indicating them within the first 24 hours would remain faulty. Furthermore, the common knowledge would suggest that if someone is in pain, some Diclofenac would be perfectly acceptable. The failure to understand this link (or, indeed, its replacement with common-sense knowledge) would most likely lead to mistranslation in interpreting, e.g. it could easily be said that 'NSAIDs are recommended within the first 24 hours'. If the interpreters were to avoid the error, they would have to be extremely alert and concentrated at this point during the lecture, which would only be possible if they worked far from their saturation level.

(2) Secondly, the interpreters felt that they lacked certain background knowledge. They felt much more comfortable as they became superficially familiarised with the following concepts, their relations (predicates) and context (a piece of extralinguistic background):

Shock and internal organs (cf., e.g. Houston 1990)

- Shock implies low systemic pressure;

- this means that peripheral tissues remain deprived of the proper amount of circulation;

- under this condition the body aims at redistributing the scarce blood supply to maintain the heart and the brain;

- kidneys remain deprived of the appropriate amount of blood, and, therefore, may sustain severe injuries - one of the reasons why kidneys are called 'shock organs' (e.g. Wardle 1998);

- evidently, one of the goals of treatment is to stabilise the circulation, i.e. to restore the quantity and quality of the blood supply;

- not before the circulation is stabilised can NSAIDs be given. Otherwise they will further undermine the blood supply in kidneys (by impairing the PG synthesis, as said above, in the previous section).

Pain, painkillers, inflammation and anti-inflammatory drugs (e.g. Slater 2010):

- injuries cause swelling, inflammation and pain; a combination of swelling and inflammation can derive from allergic reactions; pain alone can derive from malignancies;

- the three groups of substances that fit best to suppress those conditions, respectively, are NSAIDs, steroids and opioids; there are also some conditions where their indications overlap;

- the pros and cons of steroids vs NSAIDS, their combinations and applicability in a number of diseases (for instance rheumatoid arthritis in humans), as well as their combinations with other substances in asthma, COPD, SLE, etc. is a matter of long and unceasing debate in medicine; there are regularly updating studies and guidelines relevant to different disease entities that can give a hint of what the speaker's line of explanation is most likely to be. 
Lab tests and investigations:

- It is important to have at least surface knowledge of main blood-work panels used to assess the function of different organ systems and relevant for certain disease entities;

- it is also crucial to understand that very few panels, if at all, are $100 \%$ specific or reliable, which can always leave room for discussion between a speaker and their audience;

- an interpreter should have at least a basic understanding of imaging techniques and special examinations, as well as the results that they are capable of producing: e.g. ultrasound is about echogenicities, and is mainly used to examine soft tissues, while $\mathrm{x}$-ray is about opacities, and is used to examine bony structures.

(3) Thirdly, the interpreters reported a trait of the natural course of professional conversation that they had had difficulty with: the speaker chooses to elaborate on a particular professional subject, while they prefer to treat other topics much more simply, assuming the audience to have certain level of expertise. Unless the interpreter has the appropriate command of the subject in question, the only means to do the job well is, again, to resort to the journalistic-type approach. By this we mean the attempt to figure out well in advance the following: (a) what constitutes the common knowledge in a given audience; (b) what the matter of in-depth discussion is most likely to be.

(4) Different fields of medicine seem to represent variable degrees of sophistication for a lay person, as is evidenced by List 4 . Some of the subjects seem quite straightforward and easy to come to terms with, whereas others are simply unfathomable. While orthopaedics per se seems very much mechanics-related and, therefore, very visual and apparent, neurology is the total opposite. When talked about in conjunction with orthopaedics, as in our case, it is likely to immediately give a hard time to interpreters (i.e. to immediately put them beyond their saturation levels).

Again, the team spent some time getting familiarised with topical diagnosis in neurology and elucidating the following relationships (there is probably no other workaround for an interpreter but to find out this sort of information) (cf., e.g. Duus, 2005):

- Upper and lower motoneurons do not represent a particular structure; instead, these Concepts serve as a coordinate system to refer one structure relative to the other, pretty much the same as the concepts of 'proximal', 'distal', 'medial' and 'lateral' do in anatomy;

- neurons can be broadly classed into sensory and motor, with their pathways coming, respectively, upwards from the periphery into the spinal cord and then into the brain, and downwards from the brain, through the spinal cord, and to the periphery;

- some of the activities can be coordinated at the level of the spinal cord itself, without the need for the brain structures or the so-called nuclei of the spinal cord to take part (known as spinal activity, with spinal reflexes being part of this);

- brain structures, as well as the nuclei of the spinal cord, normally restrain and moderate the spinal activity; in case when the latter is high (overactive reflexes), the moderating activity lacks, which suggests the damage to the descending pathways or, indeed, the respective centres in the spinal cord or in the brain; this is referred to as the 'UMN lesion';

- UMN lesions cause hyperresponsive reflexes;

- when an executive mechanism is damaged at the level of the executive organs, this is referred to as the 'LMN lesion'; 
- LMN lesions cause hyporesponsive reflexes;

- each organ has a specific pattern of nerve supply, therefore, the manifestations of its impairment at different levels warrant more in-depth learning.

The interpreters claimed that this background would clarify many points of the presentation. Namely, the reasons behind the bladder being tense in one case and flaccid in the other, as well as the need to manually squeeze out (= to express) the content of the bladder in some patients. Certain familiarisation with topical diagnosis in neurology would seemingly clarify the examination techniques, including deep and superficial pain sensation, and would explain the usage of haemostats as an instrument for this (e.g. in eliciting limb withdrawal reflexes).

The authors are of the opinion that the problem has very much to do with the fact that the interpretants that doctors have in mind are often far from those that linguists have. Doctors and linguists use the same signs, whereas the correspondent semiotic objects are different. They have their foundations in guidelines and general medical knowledge in a doctor's case, while in a linguist's case they derive from common knowledge, common sense or dictionary definitions. In other words, the nature of semiotic objects and, indeed, predicates used by doctors is very much extralinguistic.

In order to be able to provide appropriate wordings, interpreters have to know the signs and predicates used in a given specialty in a given language. Otherwise the interpreter will, at least, sound unnatural, or even make the meaning vague. For example, the sign 'jerk' is used in neurology, as in 'hypnic jerk', 'knee jerk'. The reflex, however, is called 'the withdrawal reflex'. Should an interpreter replace this sign with a seemingly synonymous expression, e.g. 'jerk reflex', this will make listeners guess whether the 'withdrawal reflex' is meant (and, indeed, what the reason to call it otherwise really is). Even though this is unlikely to be considered a grammatical or semantic error, such a digression from routinely used wordings may be viewed as not completely appropriate by some clients.

The same holds true for predicates. A combination of signs and predicates has been shaped in medical language by professional convention. For instance, 'reflexes are elicited', 'the bladder is expressed', and 'drugs are given or 'administered'. The replacement with other predicates will make the meaning vague or even render the interpreting/translation inaccurate, as shown in some examples below: reflexes - called forth/induced/caused; bladder emptied/voided/dumped/drained (completely inappropriate, though seemingly synonymous: means that the drain has been placed, which is not necessarily the case); drug - indicated/provided/handed out. Furthermore, signs and predicates have variable and often asymmetrical equivalents in a different language. For example, the Russian name for the 'withdrawal reflex' can literally be rendered in English as 'jerk reflex', whereas 'hypnic jerk' is literally translated as 'hypnic thrust', while 'knee jerk' has a literal translation of 'knee reflex'.

Since semiotic objects and predicates used in medical discourse have extralinguistic foundations, there is one more problem that can escape interpreter's/translator's attention. These are hot spots of a given specialty. For example, the concepts of 'sepsis', 'chronic non-specific lung diseases', 'COPD', 'asthma', etc. have been revisited several times in recent years, and the revised definitions have been coined. "Definitions of sepsis and septic shock were last revised in 2001. Considerable advances have since been made into the pathobiology (changes in organ function, morphology, cell biology, biochemistry, immunology, and circulation), management, and epidemiology of sepsis, suggesting the 
need for re-examination" (Singer 2016). Or: "In 2011, the Global Initiative for Chronic Obstructive Lung Disease (GOLD) released a consensus report, Global Strategy for the Diagnosis, Management, and Prevention of COPD. It recommended a major revision in the management strategy for COPD that was first presented in the original 2001 document. Reports released in January 2013, January 2014, January 2015, and January 2016 were based on updated scientific literature ...” (GOLD 2017).

This has a number of consequences: (a) this leaves room for professional debate and ambiguous attitudes. Language users, including interpreters, may be unaware of those and, therefore, assume that such attitudes are related to the inappropriate quality of their communication; (b) interpretants may vary among the professionals themselves (e.g. not everyone in the audience may be duly updated in a timely fashion). This generates certain confusion per se. The authors are of the opinion that language users will communicate with little efficacy unless they have at least a frame of reference - i.e. unless they know some fundamentals of the debate and stay updated about the developments. Such an update, however, is not something that language users can do on their own, because there are too many updates across a wide range of different topics.

One more complicating factor is that the equivalents of certain signs in a different language may not be fully shaped. For example, with another update of guidelines coming in English, or another definition in English revisited, an official translation into a different language may lag behind. This further complicates the inherent asymmetry of signs in a given language pair. Again, this ad-hoc type of asymmetry is something that interpreters/translators may be unaware of at a given time, especially if they read up outdated guidelines.

All of the above probably explains why different medical specialties have a variable degree of sophistication for language users. Therefore, the aforementioned Index of Sophistication based on a number of criteria might be helpful. By designing a glossary of words (signs) and by elucidating the relations between the concepts (i.e. by plotting a semantic network), one can shape an array of correspondences, or a dataset. Such dataset can serve as a contingency frame of reference in case the interpreter hears the speaker say something that they find difficult to translate. Professional interpreters nowadays have to deliver their work to much higher standards (Horváth 2016:188). By using such an online tool an interpreter could at least avoid mistranslation and avoid getting lost in translation. This is probably one more reason why a web-based database seems more preferable than a mere collection of words: the database preserves the extralinguistic context of words, and is readily accessible.

This is evidenced by Lists 2 and 3. Indeed, the frame of reference would spare an interpreter from confusion in the situations when grammar creates ambiguity. Let us assume that ' $\mu$ opioid receptor agonist' has been mentioned. Which is the right way to understand this noun phrase? Is this to say that there exist ' $\mu$ receptors', or ' $\mu$ agonists', or ' $\mu$ opioids'? Whatever it is, how many more exist? Is this to say that there also exist $\alpha$, $\beta, \gamma, \delta$, etc. receptors/agonists/opioids? This level of confusion can further be exacerbated if someone from the audience or the speaker themselves use synonymous or jargon wordings: ' $\mu$ opioids (full stop)'. This can first provoke doubts as to whether or not this is the same as ' $\mu$ opioid receptor agonists', and then play a bad trick on the interpreter when they realise that this is the same and consequently take for granted the fact that a too detailed level of analysis is redundant. In this case at a later stage during the presentation they may be likely to lose the level of their alertness and not to differentiate between, for 
example, 'the urethral' and 'the ureteral' rupture or between creatinine measurements in blood vs in the abdominal tap fluid (List 3).

The example provided in this paper applies to conference interpreting rather than to interpreting at a healthcare facility. Furthermore, qualified freelance conference interpreters with medical degrees are not always readily available for a given meeting. We therefore seek to find the foundations for a viable and sustainable continued professional development (CPD) training system, whereby language users with no specialised background could receive a broader range of expertise, and complete their communicative tasks more efficiently.

Based on the authors' experience in ELT, as well as interpreting/translation, we assume that a presentation delivered by an MD or DVM at a specialised meeting has strong extralinguistic attribution. This paper provides an example of a speech in trauma and orthopaedics that can be viewed as typical, both in terms of its wordings and the contexts that it uses. We advocate that speeches in trauma and orthopaedics in general rely heavily on a number of specific backgrounds. Apart from the main subject per se, we think that such presentations necessarily have their foundations in anatomy, neurology, as well as certain domains of imaging, pharmacology and general surgery. We hypothesise that this particular pattern of backgrounds is characteristic of trauma and orthopaedics, whereas other specialties will have their own. We therefore think that the communicative task of a language user will be greatly facilitated if this pattern is specifically addressed during the learning phase (e.g. self-preparation for a meeting).

This facilitation should be reflected in subjective perceptions. Namely, the user's subjective perception of better understanding the subject and being more confident, as well as the external observer's feeling that the user knows the nuts and bolts of the subject. Subjective outcome measurements are advocated here by analogy with clinical pharmacology, whereby they are viewed as the ones that provide different and complementary prospective on a given disease. Furthermore, subjective outcome measurements are in some instances the only ones that exist (Soizic Courcier-Duplantier et al. 2003). In addition, they seem more readily available in daily communication and, therefore, can provide a more opportune starting point.

This paper attempts to articulate a particular pattern of extralinguistic backgrounds that may be typical of speeches in trauma and orthopaedics. With further speeches in this field we intend to show that this type of pattern is repeatedly found, and that the patternspecific line of self-preparation improves subjective outcomes as reported by interpreters and/or external observers. We thus aim to obtain data for a multiple-case study. The authors seek to check if further cases provide literal replication, i.e. similar results in a chain of experiments. Should 6 to 10 cases turn out as predicted, then this would confirm the consistency of our proposition (Yin 2009:54).

The approach advocated in this paper has a number of limitations. First, it involves certain subjective outcomes. However, no standardized or verified reporting tool has been proposed so far. Second, it is limited to a single case. Whether similar results could be reproduced with other speakers, and/or language users is still reserved for future research. Third, the proposed line of explanation for Interpreters was designed for a particular presentation in pelvic fractures. Whether the same design and scope of explanations will fit other subtopics in orthopaedics remains to be seen. Fourth, the alternatives to the semantic network, as well as the best way to present the information should probably become a subject of a targeted survey among prospective Databank users. 


\section{REFERENCES}

ALTE 2018. Guidelines for the Development of Language for Specific Purposes Tests available at https://www.alte.org/resources/Documents/6093\%20LSP\%20 Supplement\%20-\%20WEB.pdf (accessed 14 June 2019)

Barnitz, G. 1986. Toward Understanding the Effects of Cross-cultural Schemata and Discourse Structure on Second Language Reading Comprehension. Journal of Reading Behaviour. Volume XVIII, No. 2, 95 - 116

Bartlett, F. C. 1932. Remembering: A Study in Experimental and Social Psychology. Cambridge University Press.

California Healthcare Interpreters Association 2002. California Standards for Healthcare Interpreters. Ethical Principles, Protocols, and Guidance on Roles \& Intervention. http://www.chiaonline.org/Resources/Documents/CHIA\%20Standards/standards_chia.p df (accessed 13 October 2018)

Carrell, P. 1984a. Evidence of a Formal Schema in Second Language Comprehension. Language Learning. Vol. 34, Issue 2, 87 - 108.

Carrell, P. 1984b. Schema Theory and ESL Reading: Classroom Implications and Applications. The Modern Language Journal, Vol. 68 No IV, 332 - 343.

Chernov, G. 1994. Message Redundancy and Message Anticipation in Simultaneous Interpretation. Bridging the Gap: Empirical Research in Simultaneous Interpretation, Amsterdam and Philadelphia. John Benjamins. 139-153.

Chernov, G. 2004. Inference and Anticipation in Simultaneous Interpreting. A ProbabilityPrediction Model. Amsterdam and Philadelphia. John Benjamins.

Cohen, A. 2001 The Use of Translation Strategies in Coping with Language Learning Difficulties In: Revue française de linguistique appliquée 2001/1 (Vol. VI), 99 - 105.

Council of Europe. 2001. Common European Framework of Reference for Languages: Learning, teaching, assessment. Available at https://rm.coe.int/16802fc1bf (accessed 14 June 2019)

Duus, P. 2005. Topical Diagnosis in Neurology: Anatomy, Physiology, Signs, Symptoms. Stuttgart, New York. Thieme.

Gile, D. 1997. Conference Interpreting as a Cognitive Management Problem. In Cognitive Processes in Translation and Interpreting, ed. by Joseph H. Danks, Stephen B. Fountain, Michael K. McBeath, and Gregory M. Shreve, 196-214. Thousand Oaks, London, New Delhi. Sage Publications.

Gile, D. 1997. Conference Interpreting as a Cognitive Management Problem. In: Danks, J. H. \& Fountain, S. B. \& McBeath, M. K. \& Shreve, G. M. (eds) Cognitive Processes in Translation and Interpreting. Thousand Oaks, London, New Delhi. Sage Publications.196-214.

Gile, D. 1999. Testing the Effort Models' tightrope hypothesis in simultaneous interpretingA contribution. Hermes Vol. 23.153-172.

Global Initiative for Chronic Obstructive Lung Disease (GOLD) 2017. Global Strategy for the Diagnosis, Management and Prevention of COPD. https://goldcopd.org (accessed 13 October 2018)

Hurtado Albir, A. 2018 Competence Levels in Translation: Working Towards a European Framework. In: Interpreter and Translator Trainer 12(2), c. 111 - 131. 
Horváth, I. 2016. Information and Communication Technologies in Interpreting and Machine Interpretation. In: Horváth, I.(ed.) The Modern Translator and Interpreter, Budapest: ELTE. 183-189.

Houston, M.C. 1990. Pathophysiology of Shock. Critical Care Nursing Clinics of North America Vol. 2. No. 2. 143-149.

Keller B. 2007. Translation and Journalism The New York Times reading room. https://readingroom.blogs.nytimes.com/2007/10/31/translation-and-journalism/ (accessed 13 October 2018)

Moorkens, J. 2013. The Role of Metadata in Translation Memories. In: Pellatt V.(ed.) Text, Extratext, Metatext and Paratext in Translation. Cambridge Scholars Publishing. 79-90.

Pavlov, I.P. 1927 Conditioned Reflexes. Translated and edited by G.V. Anrep M.D., D.Sc. Oxford University Press.

Peirce, C.S. 1977. Semiotics and Significs. Ed. Charles Hardwick. Bloomington I.N. Indiana University Press.

Rackevičienė S. et al. 2019. English for Specific Purposes and The Second Foreign Language: Reaching Beyond Language Training in BA Philology Study Programme. In: The Journal of Teaching English For Specific and Academic Purposes Vol. 7, No 2, 2019, pp. $135-146$

Rumelhart, D.E. 1980. Schemata: the building blocks of cognition. In: R.J. Spiro etal. (eds), Theoretical Issues in Reading Comprehension. Hillsdale, NJ: Lawrence Erlbaum.

Salbego, N. Osborne, M. 2016 Schema activation through pre-reading activities: teaching proverbs in L2. Brazilian English Language Teaching Journal. Vol. 7. No. 2. 175 - 188 available at: https://pdfs.semanticscholar.org/e247/5dac8ec06b5c5c20d4a08 c753e9f46490bbf.pdf (accessed 14 June 2019)

Singer, M. 2016. The Third International Consensus Definitions for Sepsis and Septic Shock (Sepsis-3). The Journal of the American Medical Association. Vol. 315. No. 8. 801-810.

Slater, D. 2010. Pharmacology of Nonsteroidal Antiinflammatory Drugs and Opioids. In: Kondo, K.L., Charles, D.O., Ray, E. (eds) Seminars in Interventional Radiology. Vol. 27. No.4. 400-411.

Soizic Courcier-Duplantier et al. 2003. Subjective Outcome Measures of Drug Efficacy Therapie Vol. 58. No. 3. 267-273.

Wardle, E.N. 1998. Pathogenesis of Acute Renal Failure: Shock-kidneys. Saudi journal of kidney diseases and transplantation Vol. 9. No.3. 231 - 236.

Yin, R. K. 2009. Case study research: design and methods ( $4^{\text {th }}$ ed.), Thousand Oaks. Sage Publications, Ltd. 